\title{
Plantio de eSpécies arbóreas nativas para a Restauração ecológica na Reserva Biológica de Poço das Antas, RIO DE JANEIRO, BRASIL
}

\author{
Luiz Fernando Duarte de Moraes $^{1}$, José Maria Assumpção ${ }^{2}$, \\ Cíntia Luchiari \& Tânia Sampaio Pereira ${ }^{3}$
}

\section{Resumo}

(Plantio de espécies arbóreas nativas para a restauração ecológica na Reserva Biológica de Poço das Antas, Rio de Janeiro, Brasil) O plantio de espécies arbóreas nativas tem por objetivo acelerar a regeneração natural durante o processo de restauração de áreas degradadas. Este estudo apresenta a avaliação de 26 espécies plantadas nas áreas de baixada da Reserva Biológica de Poço das Antas, no município de Silva Jardim, RJ. Foram avaliados três plantios, com áreas variando de 0,64 a 1,17 ha. O modelo sucessional utilizado se baseou na separação das espécies em três grupos funcionais: pioneiras e secundárias iniciais, como sombreadoras, e secundárias tardias, como sombreadas. Para avaliar o desempenho das espécies, foi feito o monitoramento da adaptabilidade (taxa de sobrevivência) e do desenvolvimento (altura e diâmetro à altura do solo - DAS) das mudas plantadas. Todas as espécies de estágios iniciais utilizadas mostraram bom desempenho quanto à taxa de sobrevivência e desenvolvimento, com destaque para os valores de altura média apresentados por Citharexylum myrianthus, Schinus terebinthifolius e Trema micrantha. Após o estabelecimento das espécies sombreadoras, as tardias foram claramente favorecidas, como observado em Calophyllum brasiliense, Copaifera langsdorffii e Guarea guidonia. As espécies tardias Jacaratia spinosa e Plathymenia foliolosa apresentaram, desde o início, crescimento similar ao proporcionado pelas espécies de estágios iniciais, e podem ser classificadas como espécies pioneiras antrópicas. O modelo de plantio utilizando espécies autóctones arbóreas testado neste trabalho teve um excelente desempenho, e têm grande potencial para restabelecer processos ecológicos nas áreas degradadas da Reserva Biológica de Poço das Antas e em áreas vizinhas com características semelhantes.

Palavras chave: Restauração ecológica, floresta atlântica, regeneração natural, sucessão secundária.

\section{Abstract}

(Native tree species planting for restoration at Poço das Antas Biological Reserve, Rio de Janeiro, Brazil) Mixed plantations of indigenous tree species aims to catalyze forest regeneration in the ecological restoration of degraded areas. This work analyzes the performance of 26 tree species planted in the lowland areas at the Reserva Biológica de Poço das Antas, in Silva Jardim municipality, Rio de Janeiro State, Brazil. Three experimental plantings, with áreas ranging from 0.64 to 1.17 ha were evaluated. A successional planting model divided species into four functional groups: pioneers and early secondaries (shading species), and late secondaries and climax (shaded species). In order to evaluate the performance of the species, we evaluated survival rate and development (growth rate and diameter at the plant base - DAS) of the seedlings planted. All the early species used had a good performance, both for the survival and growth rates, especially Citharexylum myrianthus, Schinus terebinthifolius and Trema micrantha. After early species shaded the degraded site, late species grew faster, as could be observed for Calophyllum brasiliense, Copaifera langsdorffii and Guarea guidonia, suggesting the successional model is effective in accelerating Forest regeneration. Jacaratia spinosa and Plathymenia foliolosa are late species which showed fast growth, as early species do, and may be classified as anthropogenic pioneer species. The model using indigenous tree species showed an excellent performance, both for survival and growth rates, and have a great potential to restablish ecological processes in degraded areas at the Reserva Biológica de Poço das Antas and in similar areas surrounding.

Key words: Restoration ecology, atlantic rain forest, natural regeneration, secondary succession.

Artigo recebido em 03/2005. Aceito para publicação em 11/2005.

${ }^{1}$ IBAMA - Instituto Brasileiro de Meio Ambiente e Recursos Naturais Renováveis, Rod. BR 465, km 3,5, Seropédica, RJ, 23890-000. luiz.moraes@ibama.gov.br

${ }^{2}$ Instituto de Pesquisas Jardim Botânico do Rio de Janeiro. Horto Florestal. Rua Pacheco Leão, 2.040, Rio de Janeiro, RJ, 22460-030.jmaria@jbrj.gov.br

${ }^{3}$ Instituto de Pesquisas Jardim Botânico do Rio de Janeiro. Rua Pacheco Leão, 915, Rio de Janeiro, RJ, 22230-030. tpereira@jbrj.gov.br 


\section{INTRODUÇÃO}

O bioma Mata Atlântica, com sua alta biodiversidade, encontra-se entre os mais ameaçados do mundo (Mittermeier et al 1999), tem a sua degradação diretamente relacionada com o processo de ocupação adotado pelos colonizadores europeus (Dean 1996).

A ação antrópica mais devastadora para a floresta atlântica se caracterizou pelo processo de fragmentação, onde extensas áreas florestais foram convertidas em áreas urbanas, industriais e agrícolas. Seguindo um padrão observado para os trópicos, atualmente, extensas áreas são cobertas por pastagens, em sua maioria manejadas inadequadamente, ou mesmo abandonadas, significando uma drástica redução na fertilidade do solo (Aide et al. 1996). Em muitos casos, só a intervenção humana consegue converter essas pastagens novamente em florestas (Florentine \& Westbrooke 2004). O restabelecimento de florestas nativas nessas áreas requer, portanto, a aplicação simultânea de princípios ecológicos e práticas silviculturais sustentáveis (Knowles \& Parrotta 1995).

Para o estado do Rio de Janeiro há o registro de cerca de $17 \%$ de remanescentes do bioma mata atlântica, localizados nas regiões sul (a partir de Paraty, passando por Angra dos Reis, Mangaratiba até Rio Claro) e serrana, em áreas protegidas, tais como a Reserva Biológica de Tinguá, o Parque Estadual do Desengano e o Parque Nacional da Serra dos Órgãos (Fundação SOS Mata Atlântica \& INPE 2001).

As Florestas Ombrófilas Densas Submontanas, ou Matas de Baixada, dispostas ao longo da costa fluminense, foram igualmente submetidas a um severo processo de fragmentação, sendo que os poucos remanescentes desse ecossistema são verdadeiras ilhas de floresta circundadas por extensas pastagens, o que dificulta e mesmo impede sua expansão. Trabalhos de fotointerpretação indicam que quase metade da área do estado é coberta por pastagens (Fundação CIDE 2001).
A Reserva Biológica de Poço das Antas (RBPA) é um dos exemplos mais ilustrativos dessa situação. Criada em 1974 para proteger populações selvagens de mico-leão-dourado (Leontopithecus rosalia L.); a RBPA tem cerca de $40 \%$ de sua área cobertos por vegetação graminóide (Lima et al. 2006), em sua maioria originada de pastagens abandonadas, formadas em grande parte por gramíneas exóticas, competidoras eficientes e agressivas em relação às espécies nativas. Estas características facilitam a ocorrência de incêndios e dificultam a regeneração da floresta (D’Antonio \& Vitousek 1992).

Os remanescentes de Floresta Ombrófila, em diversos estágios sucessionais, não têm sido suficientes, por sua vez, para garantir a regeneração nas áreas cobertas por gramíneas e o aumento da área florestada da RBPA. As principais barreiras para a regeneração natural são um banco de sementes no solo pobre, fontes de propágulos distantes ou de baixa diversidade vegetal, ausência de dispersores, infestação por plantas invasoras e um sítio com reduzida fertilidade de solo, ou mesmo a interação entre alguns desses fatores (Cordeiro \& Howe 2001, Guariguata \& Ostertag 2001, Florentine \& Westbrooke 2004). A existência do ciclo "gramínea-fogo", entretanto, parece ser a principal barreira para a regeneração natural das áreas degradadas da RBPA.

Esse cenário estimulou pesquisadores a investigarem vários aspectos relacionados à dinâmica do processo de sucessão secundária na RBPA, a fim de subsidiar propostas para a conservação desses remanescentes (Guedes-Bruni 1998, Vieira \& Pessoa 2001, Lima et al. 2006). A principal ação conservacionista subsidiada por esses estudos foi a instalação de plantios experimentais de espécies arbóreas nativas, em modelos consorciados, cujos resultados já foram parcialmente apresentados (Moraes et al. 2002; Moraes \& Pereira 2003).

Os plantios de espécies arbóreas nativas na restauração de áreas degradadas foram 
adotados para aumentar a probabilidade de ocorrer a sucessão secundária, ou mesmo para acelerar o processo (Parrotta et al. 1997). Os plantios constituem ferramenta eficiente de regeneração artificial para a recuperação da forma e da estrutura do ecossistema (Kageyama et al. 1992a), mas antes deve-se entender quais são as barreiras para que a regeneração natural ocorra e como ela se instalaria sem intervenções antrópicas (Sayer et al. 2004). O estabelecimento de espécies nativas lenhosas pode facilitar a restauração, seja pela dispersão de propágulos (Holl et al. 2000, Silva 2003b) ou pelo sombreamento das gramíneas invasoras (Parrotta et al. 1997, Holl et al. 2000).

A restauração ecológica busca reencontrar a estabilidade e integridade biológica para um ecossistema degradado (Engel \& Parrotta 2003), não definindo previamente um ecossistema "produto", até porque os rumos da sucessão secundária são imprevisíveis. Os plantios de espécies arbóreas nativas são hoje uma importante ferramenta para a restauração de áreas degradadas, e devem servir como catalisadores da sucessão ecológica (Parrotta et al. 1997), exercendo, por exemplo, a função de atrair a fauna dispersora através do uso de espécies com dispersão zoocórica (Holl et al. 2000, Reis \& Kageyama 2003, Silva 2003b).

A elaboração de modelos para a distribuição de mudas no campo se deu através da evolução no conhecimento sobre a dinâmica das florestas tropicais, em especial o processo de sucessão secundária (Budowski 1965, Gómez-Pompa 1971). As respostas ecofisiológicas das espécies arbóreas durante a cicatrização das clareiras abertas naturalmente permitiu a sua separação em grupos ecológicos (Budowski 1965, Denslow 1980, Martinez-Ramos 1985). Os modelos de plantio que separam as espécies em grupos funcionais, chamados de modelos sucessionais, têm otimizado o potencial das espécies plantadas na restauração das áreas degradadas (Kageyama et al. 1992b).
O processo de regeneração pode ser acelerado pelo plantio de árvores isoladas ou em consórcio, encurtando o tempo para o aumento da diversidade vegetal local, ao atrair fauna dispersora tanto pela oferta de frutos quanto para empoleiramento (Toh et al. 1999, Peterson \& Haines 2000, Silva 2003b). A relação planta-animal deve ser utilizada como ferramenta para aumentar naturalmente a diversidade vegetal com a chegada de sementes de outras espécies trazidas por dispersores (Wunderlee 1997, Silva 2003b).

Além do uso do conhecimento acumulado sobre a dinâmica das florestas tropicais, é preciso, antes de definir pela ação restauradora, identificar o grau de degradação do ecossistema, o histórico de uso do solo e o que efetivamente está impedindo que o sítio degradado regenere naturalmente (Engel \& Parrotta 2003). Para a restauração em larga escala é fundamental, portanto, envolver os produtores e proprietários de terras. Plantios mistos de espécies nativas podem, além de estimular e reter a restauração da biodiversidade, funcionar como fonte de renda para pequenos proprietários rurais, (Bawa \& Seidler 1998; Leopold et al. 2001).

O presente trabalho tem por objetivo avaliar a eficiência do plantio de espécies arbóreas autóctones na restauração de áreas degradadas na Reserva Biológica de Poço das Antas, através do monitoramento da adaptabilidade (taxa de sobrevivência) e do desenvolvimento (altura e diâmetro à altura do solo - DAS) de mudas plantadas em modelos sucessionais.

\section{Material e métodos}

\section{Área de estudo}

A Reserva Biológica de Poço das Antas (5.160 ha) está localizada na região costeira central do estado do Rio de Janeiro, em área de ocorrência de uma formação florestal denominada Mata Atlântica de Baixada.

As duas principais unidades geomorfológicas da Reserva são as várzeas (temporária ou permanentemente inundadas), 
onde predominam Neossolos flúvicos, e os morrotes, com altitudes de até $200 \mathrm{~m}$ e predominância de Argissolos. O clima local é quente e úmido (Aw, de acordo com a classificação de Köppen), com uma precipitação anual média de aproximadamente $1.900 \mathrm{~mm}^{1}$, bem distribuídas ao longo do ano, com uma leve estação seca entre os meses de maio e agosto.

\section{Plantios experimentais}

Todos os plantios foram feitos com espaçamento $2 \times 2 \mathrm{~m}$, em áreas de baixada, implicando em uma densidade de 2.500 mudas/ ha, divididas em grupos ecológicas (Tab. 1) e distribuídas no campo conforme esquema apresentado na Figura 1. O preparo da área incluiu a eliminação mecanizada (uma aração e uma gradagem) da vegetação invasora associação entre Panicum maximum Jacq. (capim-colonião) e Brachiaria mutica (Forssk.) Stapf (capim-angola), com predominância da primeira, sendo que a segunda esteve restrita a manchas de alagamento potencial. As covas eram abertas pouco antes do plantio e nenhum tipo de fertilização foi utilizado.
A seleção das espécies para restauração teve como ponto de partida os levantamentos florísticos realizados na Reserva para as áreas de várzea e morrote. As espécies foram selecionadas com base em três características principais: rápido crescimento; atratividade da fauna dispersora e disponibilidade de frutos e sementes para produção de mudas. A separação das espécies em grupos ecológicos foi baseada na observação do comportamento das espécies no campo (tipo de ambiente de ocorrência, posição no estrato arbóreo) e em dados de literatura.

As mudas das espécies selecionadas foram separadas por grupos ecológicos e distribuídas no campo de acordo com um modelo sucessional (Fig. 1). Uma vez que uma das principais metas foi a de inibir o desenvolvimento das gramíneas pelo seu sombreamento, o modelo prevê que pelo menos $50 \%$ das mudas sejam espécies de rápido crescimento (pioneiras e secundárias iniciais), que promoveriam condições para o desenvolvimento das espécies de estágios sucessionais tardios. Assim, em termos funcionais, dois grandes grupos foram adotados, o das sombreadoras e o das sombreadas.

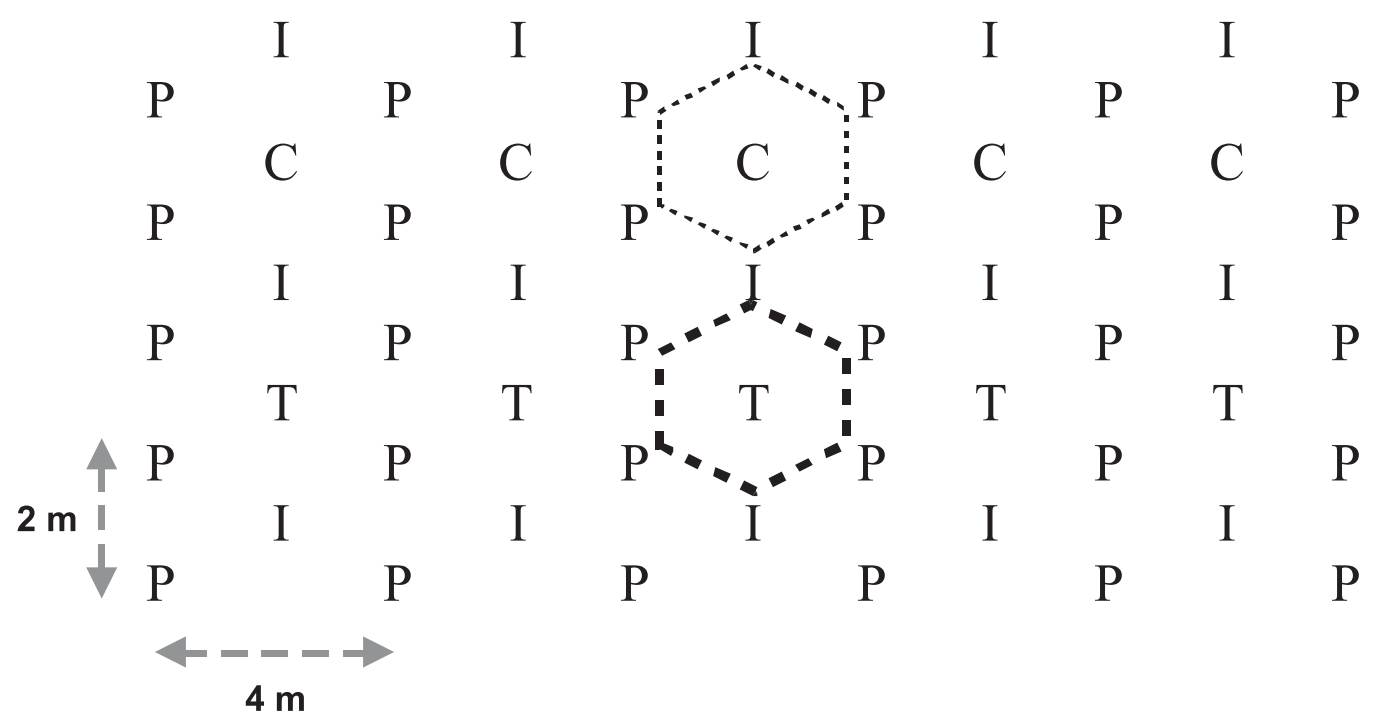

Figura 1 - Esquema do modelo sucessional de distribuição de mudas de espécies arbóreas nativas, de acordo com seus grupos ecológicos. Os polígonos tracejados sugerem o sombreamento de espécies tardias por espécies de rápido crescimento: $\mathrm{P}$ = pioneiras; $\mathrm{I}$ = secundárias iniciais; $\mathrm{T}$ = secundárias tardias; $\mathrm{C}$ = clímaxes.

${ }^{1}$ Dados coletados pelo Programa Mata Atlântica/IPJBRJ 
Tabela 1 - Espécies utilizadas em plantios experimentais na Reserva Biológica de Poço das Antas, município de Silva Jardim, Rio de Janeiro, Brasil, com respectivos tipos de dispersão de frutos e grupos ecológicos a que pertencem. Legenda: $\mathrm{GE}=$ Grupo Ecológico; $\mathrm{P}=$ pioneiras; $\mathrm{I}$ = secundárias iniciais; $\mathrm{T}$ = secundárias tardias; $\mathrm{C}=$ clímaxes; s.i. = sem informação.

\begin{tabular}{|c|c|c|c|}
\hline Espécie & Família & Dispersão & $\mathbf{G E}$ \\
\hline Área $1(0,84 \mathrm{ha})$ & \multicolumn{2}{|c|}{ Época de plantio: Maio/1996 } & \\
\hline Citharexylum myrianthum Cham. & Verbenaceae & Zoocórica/barocórica & $\mathrm{P}$ \\
\hline Margaritaria nobilis L.f. & Euphorbiaceae & Zoocórica/barocórica & $\mathrm{P}$ \\
\hline Mimosa bimисronata (DC.) O. Kuntze & Mimosaceae & Anemocórica/barocórica & $\mathrm{P}$ \\
\hline Inga affinis DC. & Mimosaceae & Zoocórica/hidrocórica & I \\
\hline Inga laurina $(\mathrm{Sw}$.$) Willd.$ & Mimosaceae & Zoocórica/hidrocórica & I \\
\hline $\begin{array}{l}\text { Pseudobombax grandiflorum (Cav.) } \\
\text { A.Robyns }\end{array}$ & Bombacaceae & Anemocórica & I \\
\hline Guarea guidonea $(\mathrm{L}$.$) Sleumer$ & Meliaceae & Zoocórica & $\mathrm{T}$ \\
\hline Jaracatia spinosa (Aubl.) A.DC. & Caricaceae & Zoocórica & $\mathrm{T}$ \\
\hline Calophyllum brasiliense Camb. & Clusiaceae & Zoocórica/hidrocórica & $\mathrm{C}$ \\
\hline Copaifera langsdorfii Desf. & Caesalpineaceae & Zoocórica & $\mathrm{C}$ \\
\hline Área 2(1,17ha) & \multicolumn{2}{|c|}{ Época de plantio: Outubro/1997 } & \\
\hline Alchornea triplinervia (Spreng.) Müll.Arg. & Euphorbiaceae & Zoocórica & $\mathrm{P}$ \\
\hline Citharexylum myrianthum Cham. & Verbenaceae & Zoocórica/barocórica & $\mathrm{P}$ \\
\hline Schinus terebenthifolius Raddi & Anacardiaceae & Zoocórica & $\mathrm{P}$ \\
\hline Trema micrantha (L.) Blume? & Ulmaceae & Zoocórica & $\mathrm{P}$ \\
\hline Inga affinis DC. & Mimosaceae & Zoocórica/hidrocórica & I \\
\hline $\begin{array}{l}\text { Pseudobombax grandiflorum (Cav.) } \\
\text { A.Robyns }\end{array}$ & Bombacaceae & Anemocórica & I \\
\hline $\begin{array}{l}\text { Sparattosperma leucanthum (Vell.) } \\
\text { K.Schum.? }\end{array}$ & Bignoniaceae & Anemocórica & I \\
\hline Tapirira guianensis Aubl. & Meliaceae & Zoocórica & I \\
\hline Nectandra oppositifolia Nees & Lauraceae & Barocórica & $\mathrm{T}$ \\
\hline Euterpe edulis Mart. & Arecaceae & Zoocórica/hidrocórica & $\mathrm{C}$ \\
\hline Posoqueria acutifolia Mart. & Rubiaceae & Zoocórica & $\mathrm{C}$ \\
\hline Área 3 (0,64ha) & \multicolumn{2}{|c|}{ Época de plantio: Agosto/1999 } & \\
\hline Citharexylum myrianthum Cham. & Verbenaceae & Zoocórica/barocórica & $\mathrm{P}$ \\
\hline Schinus terebenthifolius Raddi & Anacardiaceae & Zoocórica & $\mathrm{P}$ \\
\hline Trema micrantha (L.) Blume? & Ulmaceae Zoocórica & $\mathrm{P}$ & \\
\hline Inga affinis DC & Mimosaceae & Zoocórica & I \\
\hline $\begin{array}{l}\text { Sparattosperma leucanthum (Vell.) } \\
\text { K.Schum.? }\end{array}$ & Bignoniaceae & Anemocórica & I \\
\hline $\begin{array}{l}\text { Centrolobium tomentosum Guiilemin } \\
\text { ex Benth. }\end{array}$ & Mimosaceae & Anemocórica/barocórica & $\mathrm{T}$ \\
\hline Guapira opposita Vell. & Nyctagenaceae & s.i. & $\mathrm{T}$ \\
\hline Jaracatia spinosa (Aubl.) A. DC. & Caricaceae Zoocórica & $\mathrm{T}$ & \\
\hline Pithecellobium pedicellare DC. Benth. & Mimosaceae & Anemocórica/barocórica & $\mathrm{T}$ \\
\hline $\begin{array}{l}\text { Simira viridiflora (Allemao \& Saldanha) } \\
\text { Steyerm. }\end{array}$ & Rubiaceae s.i. & $\mathrm{T}$ & \\
\hline Dalbergia nigra (Vell.) Alemao ex Benth. & Papillionaceae & Barocórica & $\mathrm{C}$ \\
\hline Plathymenia foliolosa Benth. & Mimosaceae & Anemocórica/barocórica & $\mathrm{C}$ \\
\hline Tabebuia crysotricha (Mart. ex DC.) Standl. & Bignoniaceae & Anemocórica & $\mathrm{C}$ \\
\hline
\end{tabular}


Tabela 2 - Taxa de sobrevivência (\%), altura média (m) e DAS médio (cm) para espécies arbóreas nativas plantadas na Reserva Biológica de Poço das Antas. TS = Taxa de sobrevivência para as mudas plantadas; DAS = diâmetro médio à altura do solo. $\mathrm{N}^{\circ}=$ número indivíduos plantados/monitorados.

\begin{tabular}{|c|c|c|c|c|c|c|c|c|c|c|}
\hline \multirow[t]{2}{*}{ Espécies } & \multirow{2}{*}{$\begin{array}{c}\mathrm{N}^{\circ} \\
\text { ndivíduos }\end{array}$} & \multirow[t]{2}{*}{ TS $(\%)$} & \multicolumn{2}{|c|}{ Ano 1} & \multicolumn{2}{|c|}{ Ano 2} & \multicolumn{2}{|c|}{ Ano 3} & \multicolumn{2}{|c|}{ Ano 4} \\
\hline & & & $\begin{array}{c}\text { Altura } \\
\text { (m) }\end{array}$ & $\begin{array}{l}\text { DAS } \\
\text { (cm) }\end{array}$ & $\begin{array}{c}\text { Altura } \\
\text { (m) }\end{array}$ & $\begin{array}{l}\text { DAS } \\
(\mathrm{cm})\end{array}$ & $\begin{array}{c}\text { Altura } \\
(\mathbf{m})\end{array}$ & $\begin{array}{l}\text { DAS } \\
(\mathrm{cm})\end{array}$ & $\begin{array}{l}\text { Altura } \\
(\mathbf{m})\end{array}$ & $\begin{array}{l}\text { DAS } \\
\text { (cm) }\end{array}$ \\
\hline \multicolumn{11}{|l|}{ Área 1} \\
\hline C. mirianthum & 96 & 100 & 2,88 & 6,93 & 4,58 & 7,89 & 5,72 & 9,08 & 6,11 & 10,16 \\
\hline M. nobilis & 166 & 98,2 & 1,59 & 3,10 & 2,71 & 4,36 & 4,14 & 5,57 & 4,59 & 6,30 \\
\hline M. bimucronata & 168 & 100,0 & 3,37 & 8,35 & 5,46 & 13,45 & 6,44 & 16,88 & 6,76 & 18,58 \\
\hline I. affinis & 153 & 96,5 & 1,55 & 4,28 & 3,23 & 7,70 & 4,31 & 9,02 & 4,74 & 10,26 \\
\hline I. laurina & 18 & 100,0 & 1,57 & 3,92 & 2,70 & 6,79 & 3,38 & 7,68 & 4,29 & 9,40 \\
\hline P. grandiflorum & 257 & 98,9 & 1,78 & 7,24 & 3,01 & 10,15 & 4,30 & 11,26 & 3,72 & 10,12 \\
\hline G. guidonea & 7 & 100,0 & 1,07 & 2,56 & 2,14 & 3,70 & 3,31 & 4,82 & 4,13 & 6,61 \\
\hline J. spinosa & 154 & 95,8 & 2,33 & 8,45 & 2,86 & 10,11 & 3,95 & 9,49 & 4,19 & 12,95 \\
\hline C. brasiliense & 118 & 100,0 & 1,13 & 2,00 & 1,95 & 1,27 & 2,94 & 4,28 & 3,67 & 5,23 \\
\hline C. langsdoffii & 110 & 98,9 & 0,76 & 1,76 & 1,42 & 2,35 & 2,40 & 3,25 & 3,07 & 4,29 \\
\hline
\end{tabular}

\section{Avaliações}

Para a avaliação dos plantios experimentais foram monitorados a taxa de sobrevivência (medida um ano após o plantio) e o desenvolvimento das mudas plantadas (altura média e diâmetro à altura do solo DAS - médio).

Os dados avaliados neste estudo se referem a quatro anos de monitoramento para o plantio da área 1, e três anos para os plantios das áreas 2 e 3.

\section{Resultados E Discussão}

As Tabelas 2 e 3 apresentam os dados de taxa de sobrevivência, altura média e diâmetro médio das mudas à altura do solo para os três plantios avaliados.

\section{Taxas de sobrevivência}

As taxas de sobrevivência foram altas para todas as espécies, na maioria dos casos superior a $90 \%$, o que indica a alta adaptabilidade das espécies para a restauração de áreas degradadas nas condições estudadas, eliminando ainda a necessidade de replantio das mudas mortas. Os valores mais baixos observados no plantio da área 2 se justificam devido a um período excepcional de inundação na área plantada, resultante de uma precipitação acima da média mensal, aproximadamente 1000 mm entre os meses de dezembro de 1997 e janeiro e fevereiro de 1998, sendo que em apenas um dia de fevereiro foi registrada precipitação de 246 mm (Programa Mata Atlântica, dados não publicados).

Knowles e Parrotta (1995), em pesquisas com restauração de áreas degradadas por mineração na Amazônia, sugerem que espécies com taxa de sobrevivência a partir de $75 \%$ devem ser selecionadas para plantios. $\mathrm{Na}$ restauração de florestas tropicais secas estacionais no norte da Tailândia, o desempenho

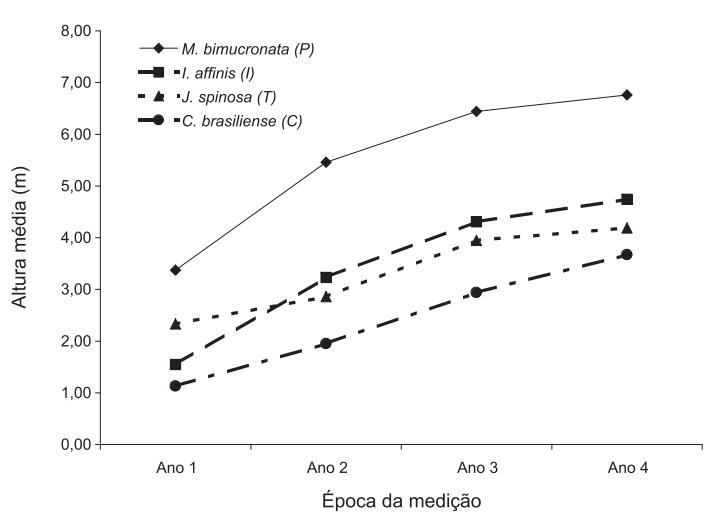

Figura 2 - Ritmo anual de crescimento de quatro espécies arbóreas nativas plantadas em consórcio na Reserva Biológica de Poço das Antas (área 1). 
Tabela 3 - Taxa de sobrevivência (\%), altura média (m) e DAS médio (cm) para espécies arbóreas nativas plantadas na Reserva Biológica de Poço das Antas. TS = Taxa de sobrevivência para as mudas plantadas; DAS = diâmetro médio à altura do solo. $\mathrm{N}^{\circ}=$ número indivíduos plantados/monitorados.

\begin{tabular}{|c|c|c|c|c|c|c|c|c|}
\hline \multirow[t]{2}{*}{ Espécies } & \multirow{2}{*}{$\begin{array}{c}\mathbf{N}^{\circ} \\
\text { indivíduos }\end{array}$} & \multirow[t]{2}{*}{ TS (\%) } & \multicolumn{2}{|c|}{ Ano 1} & \multicolumn{2}{|c|}{ Ano 2} & \multicolumn{2}{|c|}{ Ano 3} \\
\hline & & & $\begin{array}{c}\text { Altura } \\
(\mathbf{m})\end{array}$ & $\begin{array}{l}\text { DAS } \\
(\mathrm{cm})\end{array}$ & $\begin{array}{l}\text { Altura } \\
\text { (m) }\end{array}$ & $\begin{array}{r}\text { DAS } \\
(\mathrm{cm})\end{array}$ & $\begin{array}{c}\text { Altura } \\
(\mathbf{m})\end{array}$ & $\begin{array}{l}\text { DAS } \\
(\mathrm{cm})\end{array}$ \\
\hline \multicolumn{9}{|l|}{ Área 2} \\
\hline A. triplinervia & 79 & 68,6 & 2,17 & 4,90 & 3,79 & 8,72 & 5,39 & 12,31 \\
\hline C. mirianthum & 363 & 88,8 & 2,77 & 6,08 & 5,11 & 9,72 & 6,91 & 13,06 \\
\hline S. terebinthifolius & 358 & 94,1 & 2,49 & 4,94 & 3,50 & 7,03 & 4,78 & 9,50 \\
\hline T. micrantha & 75 & 61,4 & 3,50 & 7,39 & 6,54 & 11,86 & 6,81 & 13,22 \\
\hline I. affinis & 402 & 91,8 & 1,80 & 5,40 & 2,95 & 8,31 & 4,25 & 10,25 \\
\hline P. grandiflorum & 118 & 79,2 & 1,60 & 4,91 & 2,69 & 8,33 & 4,00 & 9,72 \\
\hline S. leucanthum & 83 & 84,1 & 1,63 & 2,73 & 3,82 & 6,38 & 4,87 & 10,56 \\
\hline T. guianensis & 137 & 65,7 & 1,78 & 3,03 & 3,14 & 4,84 & 4,49 & 6,09 \\
\hline N. oppositifolia & 9 & 100,0 & 0,65 & 1,06 & 0,73 & 1,08 & 1,23 & 1,41 \\
\hline E. edulis & 23 & 100,0 & 0,49 & 1,33 & 0,76 & 1,65 & 1,05 & 7,26 \\
\hline P. acutifolia & 30 & 89,1 & 1,13 & 1,65 & 2,12 & 2,63 & 2,63 & 3,24 \\
\hline \multicolumn{9}{|l|}{ Área 3} \\
\hline C. mirianthum & 253 & 99,3 & 2,71 & 5,68 & 5,36 & 8,11 & 6,77 & 10,34 \\
\hline S. terebinthifolius & 167 & 97,8 & 2,10 & 4,15 & 3,53 & 5,29 & 4,35 & 6,13 \\
\hline T. micrantha & 156 & 97,1 & 4,71 & 10,40 & 6,59 & 14,70 & 7,53 & 15,67 \\
\hline I. affinis & 386 & 98,4 & 1,30 & 2,80 & 2,84 & 4,53 & 3,71 & 5,50 \\
\hline S. leucanthum & 107 & 100,0 & 1,83 & 2,98 & 3,42 & 6,62 & 5,05 & 8,75 \\
\hline C. tomentosum & 53 & 98,2 & 1,39 & 3,42 & 3,37 & 5,41 & 3,78 & 6,62 \\
\hline G. opposita & 23 & 96,7 & 1,25 & 3,29 & 2,10 & 3,45 & 3,19 & 5,11 \\
\hline J. spinosa & 22 & 100,0 & 3,50 & 13,11 & 5,93 & 21,84 & 8,13 & 25,54 \\
\hline P. pedicellare & 13 & 94,7 & 1,36 & 1,74 & 2,94 & 3,07 & 3,70 & 3,18 \\
\hline S. viridiflora & 41 & 93,2 & 0,69 & 2,00 & 0,96 & 2,37 & 1,03 & 2,68 \\
\hline D. nigra & 40 & 95,9 & 2,17 & 2,71 & 2,94 & 4,78 & 4,74 & 5,23 \\
\hline P. foliolosa & 66 & 98,6 & 2,69 & 5,07 & 5,02 & 8,70 & 6,78 & 11,19 \\
\hline T. crysotricha & 52 & 100,0 & 1,33 & 2,79 & 2,61 & 4,01 & 3,28 & 4,38 \\
\hline
\end{tabular}

de mudas de 37 espécies arbóreas nativas foi avaliado, e foram consideradas com desempenho excelente as que apresentaram taxa de sobrevivência igual ou acima de $70 \%$ (Elliott et al. 2003).

\section{Desenvolvimento das mudas}

Os dados de crescimento anual em altura (Tabs. 2 e 3) revelam que as espécies tardias tiveram um crescimento em altura acelerado a partir do $2^{\circ}$ ano, quando o sombreamento gerado pelo crescimento das espécies pioneiras favoreceu o desenvolvimento das primeiras. A Figura 2 mostra o crescimento anual de quatro espécies da área 1, cada uma pertencendo a um grupo ecológico. A espécie clímax aumenta o ritmo de crescimento acompanhando o crescimento da pioneira; a secundária tardia, por sua vez, parece ter seu crescimento "tutorado" pela secundária inicial, como já haviam sugerido Kageyama et al. (1992b).

De uma maneira geral, duas primeiras observações podem ser feitas a partir dos dados, reforçando a eficiência do modelo sucessional: a) algumas espécies de início de sucessão têm um crescimento inicial bastante rápido, o que permite o sombreamento da área; e b) espécies de estágios sucessionais tardios têm seu 
crescimento acelerado a partir do sombreamento proporcionado pelas pioneiras.

Em estudo desenvolvido em uma bacia hidrográfica norte-americana, mudas sombreadas artificialmente apresentaram maiores taxas de sobrevivência que as não sombreadas, sugerindo que o sombreamento altera a relação de crescimento relativo entre as espécies (Sweeney \& Czapka 2004). Na Amazônia, plantio em clareiras abertas pela retirada de madeira durante manejo florestal, espécies tardias plantadas foram favorecidas pelo sombreamento gerado pelo crescimento espontâneo de espécies pioneiras, enquanto uma espécie pioneira típica (Ceiba pentandra (L.) Gaertn., também plantada), teve o seu crescimento inibido (Oliveira 2000). Na Costa Rica, Callophylum brasiliense não mostrou o mesmo nível de estresse fotossintético observado em plantas da espécie localizadas em pastagens abertas, quando cresceu $25,7 \mathrm{~cm} \pm 3$,7/ano, nos dois primeiros anos, sob árvores remanescentes com melhores taxas de desenvolvimento (Loik \& Holl 1999). Neste estudo, a partir do primeiro ano de monitoramento, quando as pioneiras já haviam sombreado a área, $C$. brasiliense cresceu a um ritmo de $84 \mathrm{~cm} \pm$ 4,7/ano, no plantio da área 1.

As espécies selecionadas como pioneiras típicas corresponderam funcionalmente, crescendo de forma bastante rápida até o terceiro ano após o plantio, como M. bimucronata (área 1), T. micrantha (áreas 2 e 3) e $C$. mirianthum (áreas 1, 2 e 3). Em dados apresentados por Barbosa (2000b), C. mirianthum, igualmente classificada como pioneira, apresentou uma altura média de 1,44 m, em avaliação feita entre os 9 e 12 primeiros meses após o plantio, valor que representa praticamente a metade da altura média registrada para a espécie, no mesmo período, no presente estudo. Além do eficiente sombreamento e combate à invasora, as espécies pioneiras podem contribuir para uma rápida melhoria na qualidade do sítio, caso de $M$. bimucronata, que retorna uma grande quantidade de nitrogênio ao solo, através da deposição de folíolos (Barbosa, 2000a), enquanto as outras duas espécies frutificaram nos primeiros 12 meses após o plantio (observações feitas durante a medição das mudas).

No plantio da área $3, J$. spinosa e $P$. foliolosa, plantadas como espécies de estágios tardios, apresentaram um padrão de crescimento similar ao das pioneiras típicas, sendo que a primeira foi a espécie com melhor desenvolvimento durante o período de monitoramento (altura média de 8,13 m e DAS médio de $25,54 \mathrm{~cm}$ ). Espécies com esse padrão de crescimento são eventualmente classificadas como pioneiras antrópicas (Kageyama \& Gandara 2000), termo que sugere que espécies tardias podem assumir um desempenho semelhante ao de pioneiras quando utilizadas na regeneração artificial. Ressalte-se que esse termo está associado simplesmente ao ritmo de crescimento da espécie, outras características de seu ciclo de vida, como longevidade, não são consideradas.

A redução na altura média apresentada pela espécie Pseudobombax grandiflorum entre os anos 3 e 4 de monitoramento pode ser explicada por uma alta incidência de quebra do caule dos indivíduos plantados. Uma provável causa para isso foi a densidade utilizada no plantio, que pode ter sido alta se comparada a densidades de populações naturais da espécie, aumentando a probabilidade da incidência de doenças, com um conseqüente aumento na taxa de mortalidade.

Os histogramas (Figs. 3, 4 e 5) com os dados de altura média para os três plantios mostram uma estratificação gradual da área plantada, sugerindo uma aproximação com a estrutura da floresta madura. Comparando plantios com vários níveis de diversidade vegetal na Austrália, observou-se que os plantios de restauração apresentaram estrutura mais complexa, dossel relativamente denso e sub-bosque contendo espécies herbáceas e arbustivas (Kanowski et al. 2003). A mesma figura sugere ainda que a composição do dossel do plantio aumenta gradativamente, o que 


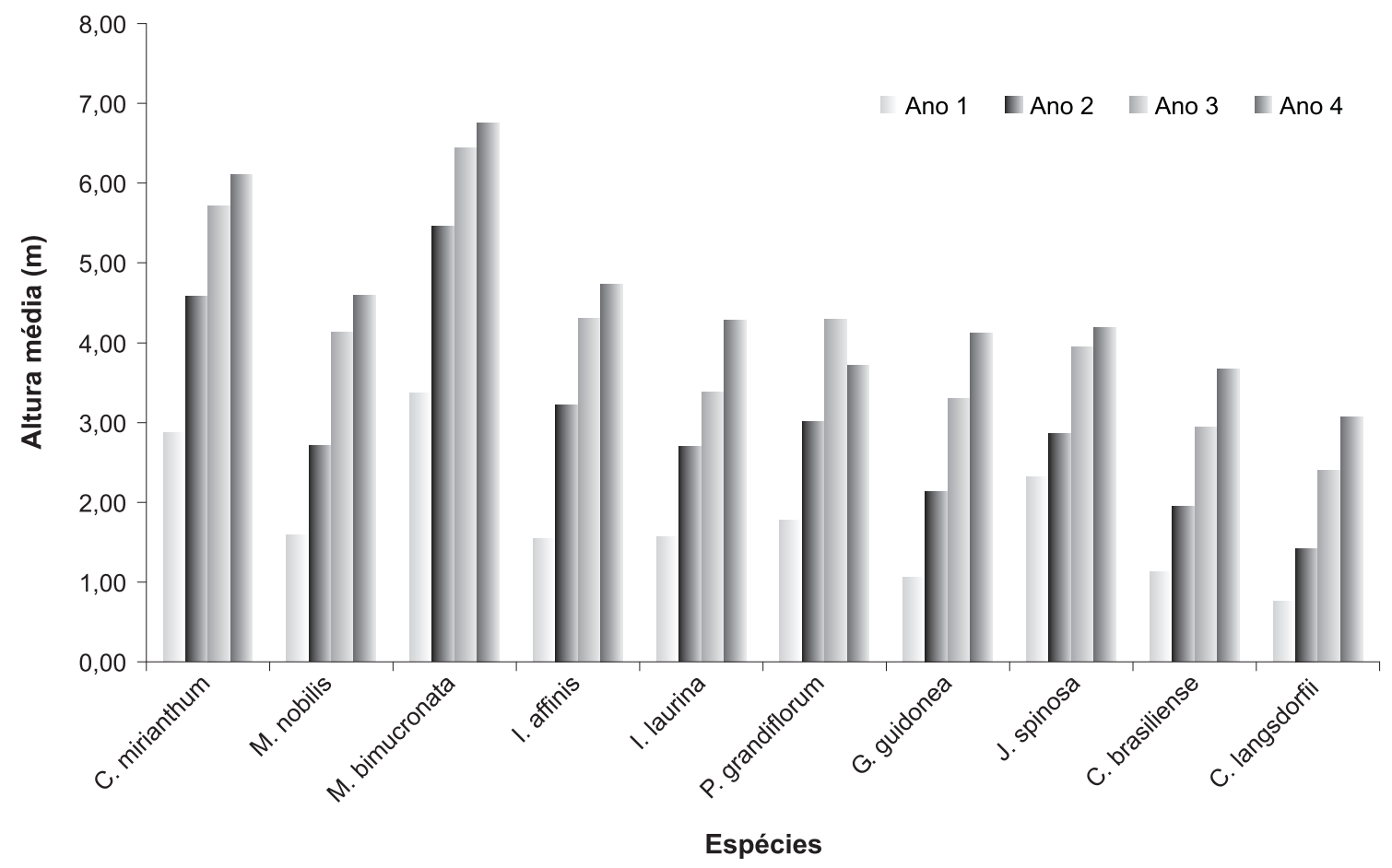

Figura 3 - Altura média (m) para espécies arbóreas nativas plantadas em consórcio na Reserva Biológica de Poço das Antas (Área 1).

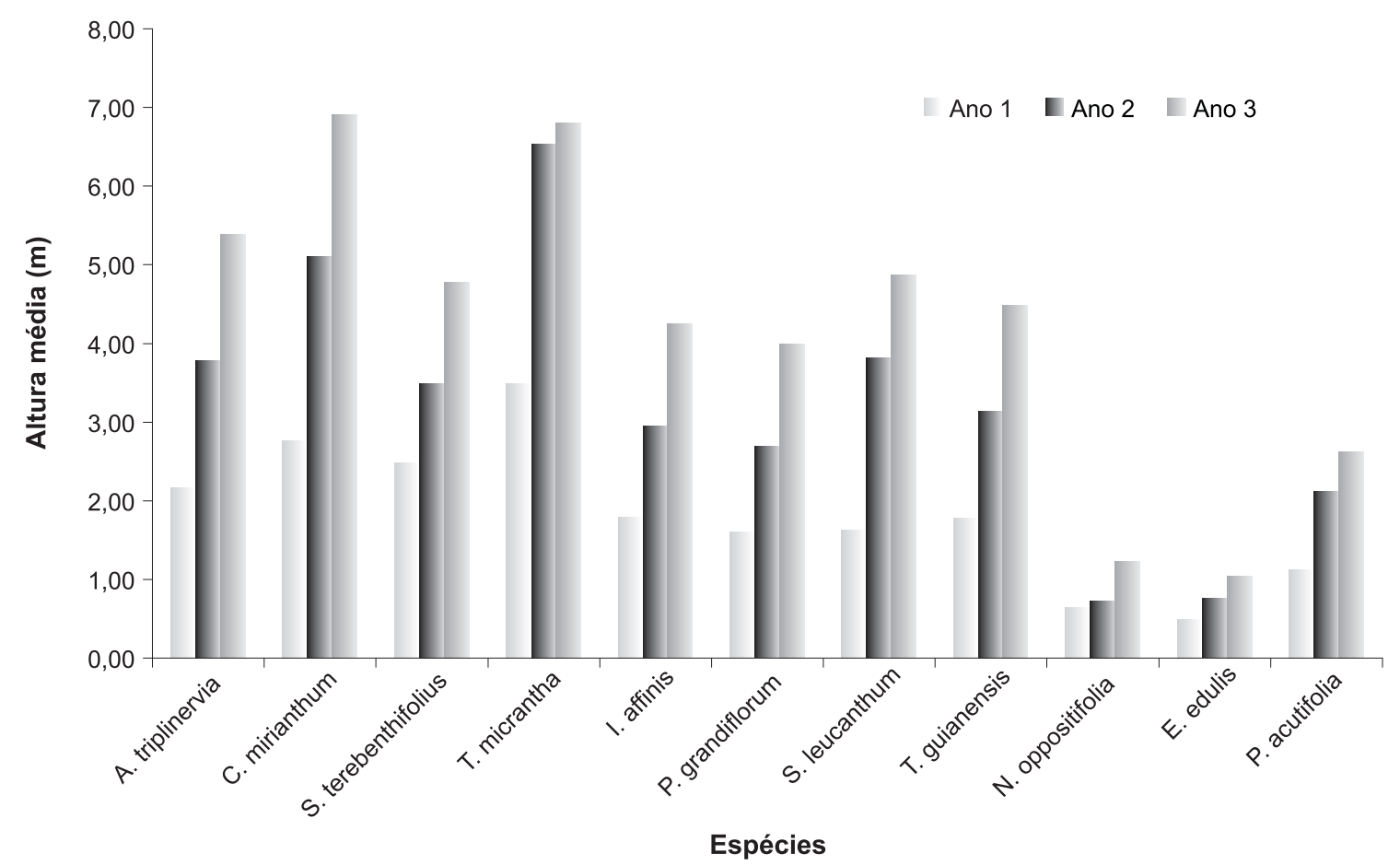

Figura 4 - Altura média (m) para espécies arbóreas nativas plantadas em consórcio na Reserva Biológica de Poço das Antas (Área 2). 


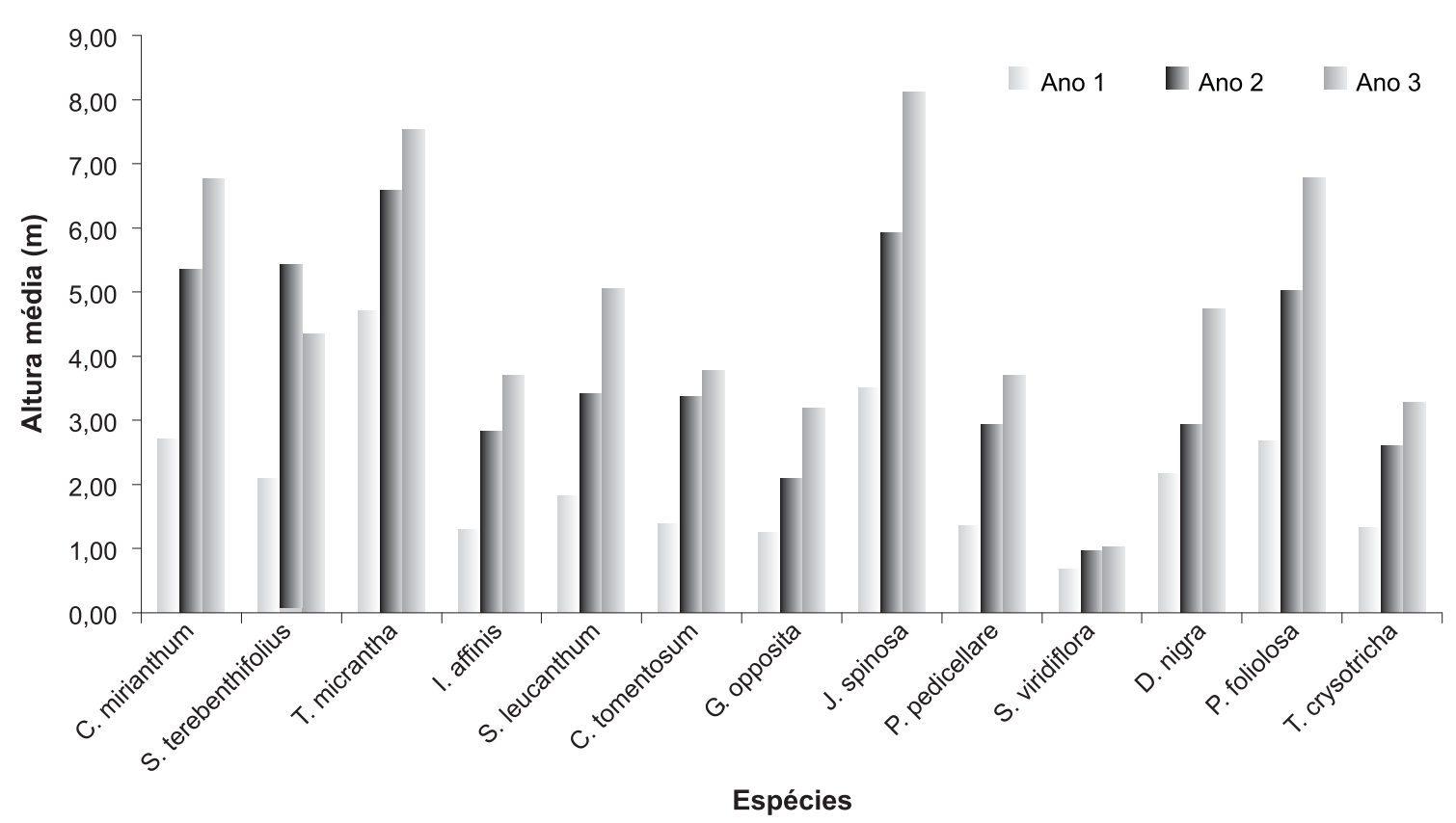

Figura 5 - Altura média (m) para espécies arbóreas nativas plantadas em consórcio na Reserva Biológica de Poço das Antas (Área 3).

aumenta a probabilidade de atração de dispersores aéreos (Wunderlee 1997). O uso de alta diversidade de espécies nos plantios (Kageyama et al. 2003) deve ser considerado, mas o uso de um número reduzido de espécies não deve ser limitante.

Ao contrário do plantio na área 1 , onde $C$. brasiliense e $C$. langsdorffii tiveram seu desenvolvimento fortemente estimulado pelo sombreamento das pioneiras, espécies secundárias tardias e clímaxes dos outros plantios, como N. oppositifolia e E. edulis (Área 2), e S. viridiflora (Área 3) cresceram muito lentamente. Esse comportamento tanto pode ser típico de espécies tardias como indicar baixa adaptabilidade ao sítio degradado. Entretanto, é importante observar também, nesse início de desenvolvimento, as taxas de sobrevivência para as espécies.

$\mathrm{Na}$ recuperação de áreas degradadas pela extração de bauxita na Amazônia, a inclusão de espécies tardias nos plantios foi muito importante para a restauração em larga escala, devido principalmente a limitações no processo de regeneração natural que inibe a dispersão de sementes e a subseqüiente colonização de outras espécies tardias (Parrotta \& Knowles 2001).

\section{Considerações Finais}

Plantios de espécies arbóreas nativas tiveram um excelente desempenho, e têm grande potencial para restabelecer processos ecológicos nas áreas degradadas da Reserva Biológica de Poço das Antas e em áreas de floresta atlântica de baixada. As altas taxas de sobrevivência das espécies plantadas sugerem uma alta adaptabilidade à condição inicial de degradação. $O$ rápido crescimento de várias espécies pode possibilitar o controle da população de espécies herbáceas invasoras e facilitar o estabelecimento do processo de sucessão. O modelo sucessional adotado para o plantio igualmente se mostrou eficiente, pois o sombreamento promovido pelas espécies de rápido crescimento (espécies de estágios iniciais) favoreceu o estabelecimento e o desenvolvimento de espécies tardias, mais longevas, aumentando a probabilidade de permanência do sistema implantado naturalmente. 
Há comportamentos e/ou respostas ecofisiológicas distintas para as espécies plantadas à condição de pleno sol, confirmando a separação em grupos ecológicos. Algumas espécies tardias, com crescimento muito lento e menor competitividade, podem ser descartadas para plantio nessas condições, e serem mais indicadas para plantios de enriquecimento.

Os plantios de espécies arbóreas nativas têm grande potencial para quebrar e/ou diminuir a agressividade das gramíneas invasoras, mas, atualmente, têm ainda um custo muito alto, o que inviabiliza sua adoção para a restauração de áreas muito extensas (Posada et al. 2000). Nesses casos, ações complementares aos plantios devem ser indicadas.

Para se avaliar o restabelecimento dos processos ecológicos, outros parâmetros podem ser sugeridos como indicadores: o retorno da fauna dispersora, a regeneração das espécies plantadas, o recrutamento de espécies não plantadas, o enriquecimento do banco de sementes do solo e até mesmo a dinâmica da matéria orgânica do solo. Na época da medição das mudas no 4o ano do plantio 1 deste estudo, por exemplo, foi observada a regeneração natural (banco de plântulas) de Schinus terebinthifolius, Inga affinis e Guarea guidonia, que participaram do plantio, e de Gochnatia polymorpha (Less.) Cabrera, Rapanea ferruginea (Ruiz \& Pav.) Mez, Dalbergia nigra, Sparattosperma leucanthum, Plathymenia foliolosa, Miconia sp. e Cecropia sp., não plantadas, favorecidas pela eliminação de gramíneas invasoras que funcionavam como barreira para a regeneração (Silva 2003a).

Correspondendo plenamente ao planejado, ou seja investir em medidas de restauração ecológica, se utilizando dos exemplos fornecidos pela regeneração natural local, os resultados apresentados neste trabalho para plantios com espécies arbóreas autóctones sugerem seu potencial para projetos contemporâneos, que objetivem o aumento de biodiversidade e o restabelecimento de serviços ambientais, como os de seqüestro de carbono e regulação climática, e os de restauração de matas ciliares e manejo de bacias hidrográficas.

\section{REFERÊNCIAS BIBLIOGRÁFICAS}

Aide, T. M.; Zimmerman, J. K.; Rosario, M. \& Marcano, H. 1996. Forest recovery in abandoned cattle pastures along an elevational gradient in northeastern Puerto Rico. Biotropica 28: 537-548.

Barbosa, H. C. 2000a. Dinâmica da serrapilheira em estágios sucessionais de floresta atlântica (Reserva Biológica de Poço das Antas-RJ). Dissertação de Mestrado. UFRRJ, Seropédica, 195p.

Barbosa, L. M. 2000b. Considerações Gerais e modelos de recuperação de formações ciliares. In: Rodrigues, R. R. \& Leitão-Filho, H. Matas Ciliares: Conservação e Recuperação. EDUSP, São Paulo, 320p.

Bawa, K. S. \& Seidler, R. 1998. Natural forest management and conservation of biodiversity in tropical forests. Conservation Biology 12(1): 46-55.

Budowski, G. 1965. Distribution of tropical American rain forest species in the light of successional process. Turrialba 15: 40-42.

Cordeiro, N. J. \& Howe, H. F. 2001. Low recruitment of trees dispersed by animals in African Forest fragments. Conservation Biology 15(6): 1733-1741.

Costa, M. L. N.; Andrade, A. C. S. \& Pereira, T. S. 1997. Fenologia de espécies arbóreas em floresta montana na reserva ecológica de Macaé de Cima. In: Lima, H. C. \& Guedes-Bruni, R. R. (eds.) 1997. Serra de Macaé de Cima: diversidade florística e conservação da Mata Atlântica. Instituto de Pesquisas Jardim Botânico do Rio de Janeiro. Rio de Janeiro. Pp.169-186.

D’Antonio, C. M. \& Vitousek, P. M. 1992. Biological Invasions by Exotic Grasses, the Grass/Fire/Cycle, and Global Change. Annual Review in Ecological Systematics 23: 63-87.

Dean, W. 1996. A ferro e fogo: a história e a devastação da mata atlântica brasileira. Companhia das Letras, São Paulo, 483p.

Denslow, J. S. 1980. Gap partitioning among tropical rainforest succession trees. Biotropica 12: 47-55. 
Elliott, S.; Navakitbumrung, P.; Kuarak, C.; Zangkum, S.; Anusarnsunthorn, V. B. \& Lakesley, D. 2003. Selecting framework tree species for restoring seasonally dry tropical forests in northern Thailand based on field performance. Forest Ecology and Management 184: 177-191.

Engel, V. L. \& Parrotta, J. 2003. Definindo a Restauração Ecológica: tendências e perspectivas mundiais. In: Kageyama, P. Y.; Oliveira, R. E.; Moraes, L. F. D.; Engel, V. L.; Gandara, F. B. (org.). Restauração Ecológica de Ecossistemas Naturais. FEPAF, Botucatu. Pp. 3-26.

Florentine, S. K. \& Westbrooke, M. E. 2004. Restoration on abandoned tropical pasturelands - do we know enough? Journal for Nature Conservation 12:85-94.

Fundação CIDE - Centro de Informações e Dados do Rio de Janeiro. 2001. IQM Verde - Índice de Qualidade de Municípios, Rio de Janeiro, RJ. (CD-ROM).

Fundação SOS Mata Attlântica \& INPE. 2001. Atlas dos Remanescentes Florestais da Mata Atlântica no período 1995-2000.

Gómez-Pompa, A. 1971. Posible Papel de la Vegetación Secundaria en la Evolución de la Flora Tropical. Biotropica 3: 125-35.

Guariguata, M. R. \& Ostertag, R. 2001. Neotropical secondary forest succession: changes in structural and functional characteristics. Forest Ecology and Management 148: 185-206.

Guedes-Bruni, R. R. 1998. Composição, estrutura e similaridade florística de dossel em seis unidades fisionômicas de Mata Atlântica no Rio de Janeiro. Tese de Doutorado. USP, São Paulo, 175p.

Holl, K. D.; Loik, M.E.; Lin, E.H.V. \& Samuels, I.A. 2000. Tropical montane forest restoration in Costa Rica: overcoming barriers to dispersal and establishment. Restoration Ecology 8(4): 339-349.

Kageyama, P. Y. ; Reis, A. \& Carpanezzi, A. A. 1992. Potencialidades e restrições da regeneração artificial na recuperação de áreas degradadas. In: Simpósio Nacional de Recuperação de Áreas Degradadas, Anais. Curitiba. Pp. 1-7.

Kageyama, P. Y.; Freixêdas, V. M.; Geres, W. L. A.; Dias, J. H. P. \& Borges, A. S. 1992. Consóercio de espécies nativas de diferentes grupos sucessionais em Teodoro Sampaio - SP. In: II Congresso Nacional sobre Essências Nativas, São Paulo, SP, Inst. Florestal de São Paulo. Pp. 527-533.

Kageyama, P. Y. \& Gandara, F. B. 2000. Revegetação de áreas ciliares. In: Rodrigues, R.R. \& Leitão-Filho, H. F. Matas Ciliares. EDUSP/FAPESP, São Paulo. Pp. 249-269.

Kanowski, J.; Catterall, C. P.; Wardel-Johnson, G. W.; Proctor, H. \& Reis, T. 2003. Development of forest structure on cleared rainforest land in eastern Australia under different styles of reforestation. Forest Ecology and Management 183: 265-280.

Knowles, O. H. \& Parrotta, J. A. 1995. Amazon forest restoration: an innovative system for native species selection based on phenological data and field performance indices. Commonwealth Forestry Review 74(3): 230-243.

Leopold, A. C.; Andrus, R.; Finkeldey, A. \& Knowles, D. 2001. Attempting restoration of wet tropical forests in Costa Rica. Forest Ecology and Management 143:243-249.

Lima, H. C.; Pessoa, S. V. A.; Guedes-Bruni, R. R.; Moraes, L. F. D.; Granzotto, S. V.; Iwamoto, S. \& Di Ciero, J. 2006. Caracterização fisionômico-florística e mapeamento da vegetação da Reserva Biológica de Poço das Antas, Silva Jardim, Rio de Janeiro, Brasil. Rodriguésia 57 (3): 369-389.

Loik, M. E. \& Holl, K. D. 1999. Photosynthetic responses to light for rainforest seedlings planted in abandoned pasture, Costa Rica. Restoration Ecology 7(4): 382-391.

Martínez-Ramos, M. 1985. Claros, ciclos vitales de los árboles tropicales y regeneración natural de las selvas altas perenifolias. In: Gomez-Pompa, A. \& Del Amo, S. 
Investigaciones sobre la regeneración de selvas altas em Veracruz. México, vol. 2. Pp. 191-239.

Moraes, L. F. D; Luchiari, C.; Assumpção, J. M.; Puglia-Neto, R. \& Pereira, T. S. 2002. Atlantic Rainforest Restoration by the Rio de Janeiro Botanic Garden Research Institute. In: Maunder, M.; Clubbe, C.; Hankamer, C. \& Grove, M. Plant Conservation in the Tropics, Londres. Pp. 151-170.

Moraes, L. F. D. \& Pereira, T. S. 2003. Restauração Ecológica em Unidades de Conservação. In: Kageyama, P. Y.; Oliveira, R. E.; Moraes, L. F. D.; Engel, V. L. \& Gandara, F. B. (org.) Restauração Ecológica de Ecossistemas Naturais. FEPAF, Botucatu. Pp. 297-305.

Oliveira, M. V. N. 2000. Artificial regeneration in gaps and skidding trails after mechanised forest exploitation in Acre, Brazil. Forest Ecology and Management 127: 67-76.

Parrotta, J. A.; Turnbull, J. W. \& Jones, N. 1997. Catalyzing native forest regeneration on degraded tropical lands. Forest Ecology and Management 99(1,2): 1-7.

Parrotta, J. A. \& Knowles, O. H. 2001. Restoring tropical forests on lands mined for bauxite: examples from the Brazilian Amazon. Ecological Engineering 17: 219-239.

Peterson, C. J. \& Haines, B. L. 2000. Early successional patterns and potential facilitation of woody plant colonization by rotting logs in premontane Costa Rican pastures. Restoration Ecology 8(4):361-369.

Posada, J. M.; Aide, T. M. \& Cavelier, J. 2000. Cattle and weedy shrubs a restoration tools of tropical montane rainforest. Restoration Ecology 8(4): 370-379.
Reis, A. \& Kageyama, P. Y. 2003. Restauração de áreas degradadas utilizando interações interespecíficas. In: Kageyama, P. Y.; Oliveira, R. E.; Moraes, L. F. D.; Engel, V. L. \& Gandara, F. B. (org.) Restauração Ecológica de Ecossistemas Naturais. FEPAF, Botucatu. Pp. 91-110.

Sayer, J.; Chokkalingam, U.; Poulsen, J. 2004. The restoration of forest biodiversity and ecological values. Forest Ecology and Management 201: 3-11.

Silva, D. C. 2003. Morfologia, recrutamento e estabelecimento de plântulas em comunidades em regeneração da Reserva Biológica de Poço das Antas - Silva Jardim, RJ. Dissertação de Mestrado. UFRJ, Rio de Janeiro, 148p.

Silva, W. R. 2003. A importância das interações planta-animal nos processos de restauração. In: Kageyama, P. Y.; Oliveira, R. E.; Moraes, L. F. D.; Engel, V. L. \& Gandara, F. B. (org.). Restauração Ecológica de Ecossistemas Naturais. FEPAF, Botucatu. Pp. 79-90.

Sweeney, B. W. \& Czapka, S. J. 2004. Riparian forest restoration: why each site needs an ecological prescription. Forest Ecology and Management 192: 361-373.

Toh, I.; Gillepsie, M. \& Lamb, D. 1999. The role of isolated trees in facilitating tree seedlings recruitment at a degraded subtropical rainforest site. Restoration Ecology 7(3): 288-297.

Vieira, C. M. \& Pessoa, S. V. A. 2001. Estrutura e composição florística do estrato herbáceo-subarbustivo de um pasto abandonado na Reserva Biológica de Poço das Antas, município de Silva Jardim, RJ. Rodriguésia 52(80): 17-29.

Wunderlee, J. M. 1997. The role of animal seed dispersal in accelerating native forest regeneration on degraded tropical lands. ForestEcology and Management 99: 223-235. 